\title{
Variation in the RAD51 gene and familial breast cancer
}

\author{
Felicity Lose1,2, Paul Lovelock1,3, Georgia Chenevix-Trench¹, Graham J Mann', Gulietta M Pupo 4 , \\ Amanda B Spurdle ${ }^{1}$ and the Kathleen Cuningham Foundation Consortium for Research into Familial \\ Breast Cancer
}

\author{
${ }^{1}$ Cancer and Cell Biology Division, Queensland Institute of Medical Research, Brisbane, Queensland, Australia \\ ${ }^{2}$ School of Medicine, Central Clinical Division, University of Queensland, Royal Brisbane Hospital, Brisbane, Queensland, Australia \\ ${ }^{3}$ School of Molecular and Microbial Sciences, University of Queensland, Brisbane, Queensland, Australia \\ ${ }^{4}$ Westmead Institute for Cancer Research, University of Sydney at Westmead Millennium Institute, Westmead Hospital, Westmead, New South \\ Wales, Australia
}

Corresponding author: Amanda B Spurdle, Amanda.Spurdle@qimr.edu.au

Received: 5 Aug 2005 Revisions requested: 13 Sep 2005 Revisions received: 28 Apr 2006 Accepted: 17 May 2006 Published: 8 Jun 2006

Breast Cancer Research 2006, 8:R26 (doi:10.1186/bcr1415)

This article is online at: http://breast-cancer-research.com/content/8/3/R26

(C) 2006 Lose et al.; licensee BioMed Central Ltd.

This is an open access article distributed under the terms of the Creative Commons Attribution License (http://creativecommons.org/licenses/by/2.0), which permits unrestricted use, distribution, and reproduction in any medium, provided the original work is properly cited.

\begin{abstract}
Introduction Human RAD51 is a homologue of the Escherichia coli RecA protein and is known to function in recombinational repair of double-stranded DNA breaks. Mutations in the lower eukaryotic homologues of RAD51 result in a deficiency in the repair of double-stranded DNA breaks. Loss of RAD51 function would therefore be expected to result in an elevated mutation rate, leading to accumulation of DNA damage and, hence, to increased cancer risk. RAD51 interacts directly or indirectly with a number of proteins implicated in breast cancer, such as BRCA1 and BRCA2. Similar to BRCA1 mice, RAD51\% mice are embryonic lethal. The RAD51 gene region has been shown to exhibit loss of heterozygosity in breast tumours, and deregulated RAD51 expression in breast cancer patients has also been reported. Few studies have investigated the role of coding region variation in the RAD51 gene in familial breast cancer, with only one coding region variant - exon 6 c.449G $>A$ (p.R150Q) - reported to date.
\end{abstract}

Methods All nine coding exons of the RAD51 gene were analysed for variation in 46 well-characterised, BRCA1/2negative breast cancer families using denaturing highperformance liquid chromatography. Genotyping of the exon 6 p.R150Q variant was performed in an additional 66 families. Additionally, lymphoblastoid cell lines from breast cancer patients were subjected to single nucleotide primer extension analysis to assess RAD51 expression.

Results No coding region variation was found, and all intronic variation detected was either found in unaffected controls or was unlikely to have functional consequences. Single nucleotide primer extension analysis did not reveal any allele-specific changes in RAD51 expression in all lymphoblastoid cell lines tested.

Conclusion Our study indicates that RAD51 is not a major familial breast cancer predisposition gene.

\section{Introduction}

Hereditary breast cancer accounts for around 5-10\% of all breast cancer cases, while the other $90-95 \%$ is assumed to be 'sporadic', with no apparent family history. A large proportion of familial breast cancer $(<40 \%)$ can be attributed to mutations in the high-risk genes BRCA1 and BRCA2 [1]. Additional breast cancer genes have been discovered, largely through disease syndromes displaying a predisposition for breast cancer. Breast cancer in families with syndromes such as Li-Fraumeni syndrome (resulting from p53 gene mutations) [2] and Cowden syndrome (the mutated PTEN gene) [3], however, are each estimated to account for less than $1 \%$ of hereditary breast cancer, and mutations in ATM (the gene mutated in ataxia telangiectasia) and CHEK2 are also predicted to account for only a small proportion of familial breast cancer $[4,5]$. The genetic basis of the large majority of familial breast cancer therefore remains unaccounted for.

It is well known that deficiencies in DNA repair can lead to carcinogenesis. Double-stranded DNA breaks (DSBs) may be the most detrimental form of DNA damage because, if left unrepaired, the detection of broken chromosomes will lead to 
cell death. Additionally, if DSBs are repaired improperly, they can result in chromosomal translocations and cancer [6]. Central to the repair of DSBs by homologous recombination is RAD51, a homologue of the Escherichia coli DNA repair protein, RecA. RAD51 functions in DNA repair by mediating homologous pairing and strand exchange reactions [7], and its importance is further supported by the presence of many highly conserved orthologues [8].

RAD51 interacts (directly or indirectly) with a large number of proteins involved in DNA repair and the cell cycle, among others, as reviewed by Richardson [9]. Interestingly, four of these proteins - BRCA1, BRCA2, p53 and ATM - have been shown to be breast cancer predisposition genes in high-risk families. Additionally, RAD51\% mice are embryonic lethal, similar to $B R C A 1 \%$ mice [10]. Alteration in either the expression or protein structure of RAD51 could therefore have similar deleterious effects on these essential pathways, leading to breast cancer.

Besides the interactions of RAD51 with key players in breast tumourigenesis, there is additional evidence to support a role for RAD51 in breast cancer. The RAD51 gene is located at chromosome position 15q15.1 [11], a region shown to exhibit loss of heterozygosity in a large range of cancers, including those of the lung, the colorectum and the breast [12]. Specifically, 70\% of breast tumours (from subjects with an unknown family history) [12] and 32\% of sporadic (nonfamilial) breast cancers have been found to exhibit loss of heterozygosity of this region [13]. RAD51 expression has also been found altered in both primary tumours and cancer cell lines. RAD51 mRNA expression in $16 / 16$ of tumours from BRCA1/2 mutation-negative familial breast cancer patients was found to be one-half of that of the BT-474 breast cancer cell line [14], and protein levels were found to be decreased in $30 \%$ of breast tumours from a combination of sporadic and high-risk breast cancer patients [15].

In contrast, there are reports of increased RAD51 expression in tumours and cancer cell lines. Ma and colleagues [16] detected an increase in RAD51 mRNA expression in Ductal Carcinoma In Situ-Invasive Ductal Carcinoma transition and high-tumour-grade breast cancers, while it has also been found that overexpression of RAD51 correlates with histological grading of Invasive Ductal Carcinoma [17]. There are numerous reports of RAD51 overexpression in a large range of cancer cell lines, including cervical cancer, prostate cancer and breast cancer [18].

These RAD51 expression data are difficult to reconcile with a suppressor function, as suggested by the loss of heterozygosity data and knockout mouse data. Instead, the data suggest that any dysregulation of RAD51 may be associated with downstream biological and clinical effects. Indeed, it has been demonstrated that homologous pairing and strand transfer, essential events in the repair of DSBs, require stoichiometric amounts of RAD51 such that overexpression or underexpression of RAD51 results in a lack of formation of structures fundamental in the DSB repair process [19].

Despite the presented evidence for a role for deregulated expression of RAD51 in DSB repair defects and/or breast cancer, there have been few studies assessing the effects of RAD51 gene variation on breast cancer risk. These have largely focused on assessing the risk associated with a polymorphic variation in RAD51. Although there is some evidence that the rare $-135 \mathrm{G}>\mathrm{C}$ variant in $R A D 51$ is involved in modify-

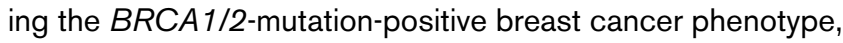
studies focusing on the association between the RAD51 $135 \mathrm{G}>\mathrm{C}$ and $-172 \mathrm{G}>\mathrm{T}$ variants and breast cancer risk using case-control analysis have shown little support for a significant association with breast cancer [20].

With regard to RAD51 mutations and cancer predisposition, three studies have used various mutation detection methodologies to screen RAD51 in breast cancer patients. An analysis of 93 early-onset breast cancer cases, $9 \%$ of which had a strong family history, revealed no coding region variation [21]. A second study in 2000 assessed a Japanese population of 45 well-characterised high-risk breast cancer patients using single-strand conformation polymorphism (SSCP) analysis and detected one relatively rare variant, an arginine for glutamine substitution at amino acid 150 (c.449G>A) [22]. No other sequence alterations were detected in the Japanese study. Rapakko and colleagues [23] recently used conformation-sensitive gel electrophoresis to investigate 74 high-risk and 52 moderate-risk breast and/or ovarian cancer families of Finnish descent. All of the variation detected was noncoding and a majority was found in both cases and controls. It has been reported, however, that the sequence variation detection sensitivity of conformation-sensitive gel electrophoresis and SSCP is around $75 \%$ and $60-85 \%$, respectively $[24,25]$, and it is possible that some variation was not detected. We therefore sought to determine whether there is a role for variation in the entire RAD51 coding region (and surrounding intronic regions) in index cases from a well-characterised set of 49 $B R C A 1 / 2$ mutation-negative breast cancer families, using the highly sensitive technique denaturing high-performance liquid chromatography (DHPLC). These families included a subset of families where cancer-affected individuals were shown to share a haplotype around the RAD51 locus. We also screened index cases from 71 families specifically for the previously reported $R A D 51$ p.Arg150Gln variant [22].

\section{Methods \\ Participants}

Multiple-case breast cancer families were ascertained through the Kathleen Cuningham Foundation Consortium for Research into Familial Breast Cancer [26]. Ethics approvals were obtained from the Ethics Committees of the Peter MacCallum 
Table 1

\begin{tabular}{|c|c|c|c|c|c|c|}
\hline Exon & PCR fragment & Forward primer & Reverse primer & $\begin{array}{l}\text { Annealing } \\
\text { temperature }\left({ }^{\circ} \mathrm{C}\right)^{a}\end{array}$ & Size (bp) & $\begin{array}{l}\text { DHPLC } \\
\text { temperature }\left({ }^{\circ} \mathrm{C}\right)\end{array}$ \\
\hline 1 & 1 & GCAAGCGAGTAGAGAAGTGGA & AACTGCCGCTGAGCACTG & 54 & 218 & 65 \\
\hline 2 & 2 & ATGGCCTTGGCTTTTCCTAA & GGCCCTGCCAGACATATTTA & 54 & 391 & 57 \\
\hline 3 & 3 & TGGAACCAACTTCCCATCTC & TTСССАСТААТGССТСССТА & 54 & 341 & 58 \\
\hline 4 & 4 & СТСТTСССАТTGСАСАССТT & САСCTGGCCTTCCTCTATCTC & 54 & 371 & 52,57 \\
\hline 5 & 5 & TCTGATGAGCTCCAAGAACA & TGACATGGAAGGATTTTGAAG & 51 & 344 & 58 \\
\hline 6 & 6 & AAGGGAATGCCTCCTTCCTA & CCAAACTAACCCTGGCAATC & 54 & 314 & 59 \\
\hline 7 & 7 & САAATTGCTCATCTGCCTG & TGAGGCACCGTTTAACAAGA & 54 & 397 & 59 \\
\hline 8 & 8 & TGGTAAGGAAGGGACCAGAA & TGTGGCCATAGACACTCCAA & 57 & 390 & 60 \\
\hline 9 & 9 & TCGTTATTTTGTGGGGGAAA & ACAGGGGAGAGGCATATCAA & 54 & 447 & 58 \\
\hline 10 & $10 a$ & TTGGTGCTTTGGTCTGTGTC & АТАССССТССТССААААССА & 54 & 409 & 59 \\
\hline 10 & $10 b$ & CAGGAGACAGGTCAGTAGTCACA & AGGTTTGGCACAAGACTCCA & 51 & 374 & 57 \\
\hline 10 & $10 \mathrm{c}$ & TGATCTTGTGTAAGGGTTTGGTT & GCAATCTCGACTCACTGCAA & 51 & 375 & 60 \\
\hline 10 & $10 \mathrm{~d}$ & GATAGCCTGAGGTGGGAGAA & TCTGCAAGTGGGACTTTCCT & 54 & 319 & 60 \\
\hline
\end{tabular}

a'Touchdown' PCR amplification conditions were as follows: denaturation at $94^{\circ} \mathrm{C}$ for 10 minutes, followed by two cycles of $94^{\circ} \mathrm{C}$ for 30 seconds, 30 seconds at the fragment annealing temperature $\left(T_{A}\right)+6^{\circ}$, and $72^{\circ} \mathrm{C}$ for 30 seconds. The conditions remained the same for the rest of the PCR except for the annealing temperature, which consisted of two cycles at $\left(T_{\mathrm{A}}+4^{\circ} \mathrm{C}\right)$, then two cycles at $\left(T_{\mathrm{A}}+2^{\circ} \mathrm{C}\right)$ and, finally, $35 \mathrm{cycles}$ at the $T_{\mathrm{A}}$. A final extension step was conducted at $72^{\circ} \mathrm{C}$ for 7 minutes.

Cancer Institute and the Queensland Institute of Medical Research, and all participants gave written informed consent.

Inclusion criteria for this study included the following seven situations: criterion 1, the family contained four or more cases of breast cancer or contained at least three breast cancer cases, one of which possessed 'high-risk' features such as age at onset $<40$ years of age, the presence of male breast cancer in the family, bilateral breast cancer or ovarian and breast cancer in the same subject; criterion 2, at least two of the breast cancer cases in the family were alive, along with four or more living, unaffected, female first-degree or second-degree relatives over 18 years of age; criterion 3 , three or more blood samples from breast cancer cases (on the same side of the family) were available; criterion 4, no pathogenic mutation in BRCA1 or $B R C A 2$ had been identified in the family; criterion 5 , no variants of unknown pathogenic significance in BRCA1 or $B R C A 2$ had been identified in the family; criterion 6 , a total of 11 or more blood samples from the family were available for genotyping analysis; and criterion 7 , where data were available for a limited number of families, RAD51 haplotype sharing analysis (D15S1012, D15S994 and D15S978 located within $2 \mathrm{Mb}$ of RAD51) showed evidence of a haplotype shared by affected participants in the RAD51-containing region, $15 q 15.1$.

Fifty per cent of index cases (the youngest available breast cancer case) had been tested by diagnostic laboratories for mutations in BRCA1 and BRCA2 by full sequencing. There were no differences in allele frequency for any $R A D 51$ variant when cases screened for BRCA1/2 mutation were compared with the total breast cancer sample.

A total of 73 index cases from 71 families fitting the first four criteria were genotyped for the RAD51 exon 6 c. $449 \mathrm{G}>\mathrm{A}$ (p.Arg150Gln) variant. A total of 51 index cases from 46 families fitting all seven criteria were screened for variation across the entire RAD51 coding region. A small overlap of five individuals from five families was analysed using both approaches. Multiple index cases were screened from a given family when it contained two cases with the same age at onset of breast cancer. For families screened across the entire RAD51 coding region, four families also contained individuals with either testicular or ovarian cancers and, if available, these subjects were also screened for variation in $R A D 51$ due to the high expression of RAD51 in these tissues [22].

A control population of one of each pair of 93 unrelated, female, monozygotic twins (from a sample of 3,348 twin pairs described previously) was analysed to determine the control frequency of any variation detected in the RAD51 gene in this study. Individuals were almost exclusively of European origin and had been recruited through the Australian Twin Registry [27].

\section{RAD51 variation analysis}

The RAD51 c.449G>A (p.Arg150GIn) variant was screened using $P C R$ and restriction fragment length polymorphism analysis. Forward primer AAGATGTCATGAGGAGCTTGG and reverse primer GCCATAGTCTCTCTTATCTAAACCAG spanned the Mspl site present in the wildtype sequence (and 
Table 2

\begin{tabular}{|c|c|c|c|c|c|}
\hline Gene region & PCR fragment & Nucleotide change & Amino acid change & $\begin{array}{l}\text { Number (\%) of } \\
\text { heterozygous families }\end{array}$ & $\begin{array}{l}\text { Number (\%) of } \\
\text { heterozygous controls }\end{array}$ \\
\hline Exon 1 (5' UTR) & 1 & c. $-135 G>C$ & - & $3 / 28(10.7 \%)$ & N/D \\
\hline Exon 1 (5' UTR) & 1 & c. $-172 \mathrm{G}>\mathrm{T}$ & - & 16/33 (48.5\%) & N/D \\
\hline Intron 2 & 2 & c. $97+110 A>G$ & - & $3 / 46(6.5 \%)$ & $16 / 93(17.2 \%)$ \\
\hline Intron 3 & 4 & c. $226-33 T>G$ & - & $11 / 46(23.9 \%)$ & $23 / 93(24.7 \%)$ \\
\hline Intron 3 & 4 & c. $226-70 T>A$ & - & $20 / 46(43.5 \%)$ & $43 / 93(46.2 \%)$ \\
\hline Intron 3 & 4 & c. 226-72delA & - & $2 / 46(4.3 \%)$ & $8 / 93(8.6 \%)$ \\
\hline Intron 3 & 4 & c. $226-33 T>G$ and c. $226-70 T>A$ & - & $4 / 46(8.7 \%)$ & 8/93 (8.6\%) \\
\hline Intron 3 & 4 & c. $226-33 T>G$ and c.226-72delA & - & $1 / 46(2.1 \%)$ & $0 / 93(0 \%)$ \\
\hline Intron 3 & 4 & c. $226-70 \mathrm{~T}>\mathrm{A}$ and c.226-72delA & - & $1 / 46(2.1 \%)$ & 6/93 (6.5\%) \\
\hline Intron 4 & 5 & c. $344-36 \mathrm{~T}>\mathrm{G}$ & - & $3 / 46(6.5 \%)$ & 16/93 (17.2\%) \\
\hline Exon 6 & 6 & c. $449 G>A$ & p.R150Qb & 0/46 (0\%), 0/66 (0\%) & N/D \\
\hline Intron 7 & 7 & c. $644+57 \mathrm{G}>\mathrm{T}$ & - & $1 / 46(2.2 \%)$ & $0 / 93(0 \%)$ \\
\hline Intron 8 & 9 & c. $775-41 \mathrm{G}>\mathrm{C}$ & - & $1 / 46(2.2 \%)$ & N/D \\
\hline Exon 10 (3' UTR) & $10 \mathrm{~b}$ & c. $1020^{*}+502 T>G$ & - & $19 / 46(41.3 \%)$ & N/D \\
\hline Exon 10 (3' UTR) & $10 c$ & c. $1020^{*}+718 \mathrm{G}>\mathrm{A}$ & - & $18 / 44(40.9 \%)$ & N/D \\
\hline Exon 10 (3' UTR) & $10 d$ & c. $1020^{*}+927 T>C$ & - & $17 / 42(40.4 \%)$ & N/D \\
\hline
\end{tabular}

UTR, untranslated region; N/D, not determined aValues expressed as the number of heterozygous families because all related individuals shared the same genotype. bReported in Kato and colleagues [22].

lost in the A allele). PCR reactions were carried out in a $20 \mu \mathrm{l}$ mixture containing $15 \mathrm{ng}$ genomic DNA, $800 \mathrm{nM}$ each primer, $200 \mu \mathrm{M}$ each dATP, dCTP, dGTP and dTTP (Promega, Madison, WI, USA), $1.5 \mathrm{mM} \mathrm{MgCl}, 1 \times \mathrm{PCR}$ buffer and $1 \mathrm{U}$ AmpliTaq Gold polymerase (PE Applied Biosystems, Foster City, CA, USA). PCR amplification conditions were 5 minutes initial denaturation at $94^{\circ} \mathrm{C}, 30$ cycles of 20 seconds at $94^{\circ} \mathrm{C} / 20 \mathrm{~s}$ at $55^{\circ} \mathrm{C} / 20 \mathrm{~s}$ at $72^{\circ} \mathrm{C}$, and 10 minutes final extension at $72^{\circ} \mathrm{C}$. Mspl (NEB, Ipswich, MA, USA) digestion (as specified by the manufacturer) of the $205 \mathrm{bp}$ PCR product yielded fragments of $89 \mathrm{bp}$ and $116 \mathrm{bp}$ for the wildtype $\mathrm{G}$ allele, with a single fragment of $205 \mathrm{bp}$ for the A allele. Digested PCR products were separated on a $4 \%$ Nusieve agarose gel.

Primers encompassing the 10 exons of RAD51 (and surrounding intronic regions) (Hs.446554; Unigene, NCBI) were designed using Primer3 software [28] (Table 1). PCR reactions were carried out in a $20 \mu \mathrm{l}$ mixture containing, at final volume, 15 ng genomic DNA, 20-40 pmol each primer, $200 \mu \mathrm{M}$ each dATP, dCTP, dGTP and dTTP (Promega), 1.5-2 mM $\mathrm{MgCl}_{2}, 1 \times$ PCR buffer and $1 \mathrm{U}$ AmpliTaq Gold polymerase (PE Applied Biosystems). For some fragments, 0.5-1 M betaine was utilised to improve PCR and/or DHPLC profiles. The 'touchdown' PCR amplification conditions are detailed in Table 1. All products (and $\mathrm{H}_{2} \mathrm{O}$ controls) were first visualised on a $1.5 \%$ agarose gel before denaturation by heating to $95^{\circ} \mathrm{C}$ for 5 minutes and cooling to $60^{\circ} \mathrm{C}$ over a period of 30 minutes.
Samples were analysed on a Varian Helix DHPLC system (Varian, Palo Alto, CA, USA) at the recommended melt temperature(s) as determined by the Stanford DHPLC Melt Program [29] (detailed in Table 1). Analysis of the results was carried out using Star Workstation Reviewer software (version 5; Varian) and any aberrant or shifted profiles were reamplified for repeat by DHPLC before being sequenced using the Big-Dye version 3.1 sequencing chemistry and PE Applied Biosystems 377 sequencer.

\section{Allelic expression analysis (single nucleotide primer extension)}

Lymphoblastoid cell lines (LCLs) were derived from individuals previously assessed for RAD51 variation and found to possess common single nucleotide polymorphisms (SNPs). All lines were grown in RPMI 1640 media with 10\% foetal calf serum and $1 \%$ penicillin/streptomycin. RNA was extracted from LCLs using TriReagent (Sigma Chemicals, Perth, WA, Australia) according to the manufacturer's instructions. The RNA quality was checked by northern gel analysis and $1 \mu \mathrm{g}$ each sample was placed in a reverse transcription-PCR reaction using Superscript III RNAse $\mathrm{H}^{-}$Reverse Transcriptase, according to the manufacturer's instructions (Invitrogen, Carlsbad, CA, USA). PCR was then performed using the $R A D 51$ exon $10 \mathrm{c}$ primers (Table 1), and the resulting product was purified using a Qiagen PCR purification kit (Qiagen, Hilden, Germany). 
Primers located directly adjacent to the exon 10 c. $1020^{*}+718 \mathrm{G}>\mathrm{A}$ SNP (forward primer, TTAAGTCCAGCTTGGCCAAG; and reverse primer, TGTAGAGATGGGATTTCACCA) were then used in single-cycle PCR reactions incorporating radiolabelled dNTPs. Both forward and reverse reactions were performed to verify results. Radiolabelled fragments were separated on a $10 \%$ denaturing acrylamide gel, and were visualised by autoradiography [30]. Densitometric analysis was performed using Fujifilm Multigauge 2003 software (Fuji Photo Film Co., Tokyo, Japan).

\section{Results}

The c.449G >A (p.Arg150Gln) variant was not detected in any of the 71 families genotyped directly for this variant, nor was it detected by DHPLC screening across this region in an additional $\mathbf{4 1}$ families.

DHPLC analysis of 51 index breast cancer cases from 46 families with a strong family history revealed 13 different sequence variations, all of which were located in noncoding regions (Table 2).

The intron 7 and intron 8 variants have not been previously described. The intron 7 c.644+57G $>$ T variant was not found in control subjects. This variant is not thought to be pathogenic, however, because, although the $\mathrm{G}$ nucleotide is conserved in the chimpanzee, the mouse and the rat [31], the variant is deeply intronic and is not predicted to alter splicing using the SpliceSiteFinder prediction program [32]. The intron 8 (c.775-41G $>$ C) variant was not tested for in controls, but it is also unlikely to be functional due to its deep intronic location and the lack of predicted splicing effects.

All of the remaining five variants occurred at greater frequency in controls than cases. The intron $2(\mathrm{c} .97+110 \mathrm{~A}>\mathrm{G})$ and intron 4 (c.344-36T>G) variants appeared to occur on the same haplotype in all cases and controls. Variants detected in the $5^{\prime}$ untranslated region and the 3 ' untranslated region were common SNPs that have been reported previously, and were found in this population at the expected frequencies.

To assess the possibility that allelic imbalance of RAD51 expression may occur in breast cancer patients, we chose a common exonic SNP - exon 10 c. $1020^{*}+718 \mathrm{G}>\mathrm{A}$ - as a marker of RAD51 gene expression, and we assessed four LCLs from individuals heterozygous for these variants using single nucleotide primer extension. The experiment was performed in both forward and reverse directions and was conducted twice, allowing verification of results. In all LCLs tested there was no evidence of one allele being favourably expressed over the other allele (data not shown).

\section{Discussion}

RAD51 plays a central and critical role in the DNA repair process and also interacts with a number of proteins involved in important pathways, such as cell-cycle regulation and DNA damage signalling. Four studies have investigated the coding region of $R A D 51$ for variation in breast cancer to date. Bell and colleagues [21] screened 93 early-onset ( $<40$ years) breast cancer cases, $9 \%$ of which had a strong family history, for mutations in RAD51. A yeast-based protein truncation assay revealed no truncating mutations, and sequencing of a subset of 27 individuals with age at onset $<30$ years revealed no coding region variation. In the same study, a protein truncation assay of 15 breast cancer cell lines also revealed no truncating mutations.

Schmutte and colleagues [33] screened the RAD51 coding region and the surrounding intron/exon boundaries in 41 breast carcinomas (family history unknown) by SSCP but found no mutations.

There has been one report of a missense variant in $R A D 51$ being detected in a breast cancer population to date. In a Japanese population of 20 breast cancer cases with a strong family history and 25 individuals with other high-risk factors such as bilateral breast cancer, and so on, a $G>A$ nucleotide substitution was detected by SSCP in two individuals with bilateral breast cancer, which results in an arginine residue being substituted for a glutamine residue at amino acid position 150 of RAD51 [22]. This was an interesting finding as glutamine and arginine possess quite different physical properties that could be predicted to affect the RAD51 protein. No other coding region variation was detected, but the sensitivity of SSCP to detect variation is reported as only $60-85 \%$ [25].

In the present study we failed to detect the $R A D 51$ c.449G $>\mathrm{A}$ (p.R150Q) variant in a large, well-characterised Australian familial breast cancer sample set. Our study assessed 112 high-risk breast cancer families for this variant, with our inclusion criteria (see Methods, first inclusion criterion) being similar to those of Kato and colleagues [22] aside from the fact that the BRCA1/2 mutation status was not reported in the Japanese study. The p.R150Q variant has not been reported in the National Center for Biotechnology Information (NCBI) SNP database [34] but it appears that it may be a relatively rare population-specific variant, and is probably not relevant to breast cancer in the Australian population.

Rappako and colleagues [23] recently used conformationsensitive gel electrophoresis to screen 74 high-risk and 52 moderate-risk Finnish breast and/or ovarian cancer families for variation in the RAD51 gene. The inclusion criteria for a 'highrisk' family was similar to the current study, but we specifically investigated breast cancer patients and several families that shared a haplotype in the RAD51 region. In addition, DHPLC has been reported to be a more sensitive technique for detecting sequence variation [24]. Similar to the current study, no coding region variation was detected. 
We did not detect any coding region variation in the RAD51 gene using the highly sensitive mutation detection technique DHPLC. A number of intronic variants were found. All variants, however, were either present at a similar frequency in controls and/or were located deep in the intron, and were therefore predicted not to have any functional effects. Additionally, single nucleotide primer extension analysis did not reveal any change in expression of RAD51 in LCLs from breast cancer patients, indicating that there is little, if any, allelic effect on $R A D 51$ expression due to known or undetected genetic variation.

\section{Conclusion}

The aim of the present study was to attempt to elucidate a role for $R A D 51$ as a high-risk breast cancer predisposition gene using DHPLC and well-characterised non-BRCA1/2 familial breast cancer patients. We did not detect any variation in the coding region of $R A D 51$, which may further imply the importance of maintaining the structural integrity of such a vital component of the DNA repair pathway. Although other noncoding variation in the RAD51 gene may be involved in BRCA1/2mutation-negative breast cancers, the absence of coding or untranslated region mutations in this set of well-characterised familial cases implies that $R A D 51$ is not a major familial breast cancer predisposition gene.

\section{Competing interests}

The authors declare that they have no competing interests.

\section{Authors' contributions}

FL carried out the screening of the gene and drafted the manuscript. PL performed the single nucleotide primer extension analysis, and GJM and GMP performed the haplotype sharing analysis. The Kathleen Cuningham Foundation Consortium for Research into Familial Breast Cancer recruited and collected individuals for the study. GC-T participated in the design and coordination of the study. ABS conceived the study, and participated in its design and coordination, and helped to draft the manuscript. All authors read and approved the final manuscript.

\section{Acknowledgements}

The authors would like to thank Helena Kelly and Xiaoqing Chen for technical assistance, Heather Thorne, Lynda Williams and Danni Surace for DNA preparation, the Kathleen Cuningham Foundation Consortium for Research into Familial Breast Cancer (kConFab) research nurses and staff of the Familial Cancer Clinics for data collection, the kConFab Central Registry staff and Helene Holland for supplying data, and the families for their participation. $\mathrm{kConFab}$ is supported by the National Health and Medical Research Council (NHMRC) of Australia, the National Breast Cancer Foundation of Australia, and the Cancer Councils of Queensland, of New South Wales, of Western Australia, of South Australia, and of Victoria. This study was funded by grants from NHMRC and NBCF. ABS has an NHMRC Career Development Award and GC$T$ is an NHMRC Senior Research Fellow.

\section{References}

1. Ford D, Easton DF, Stratton M, Narod S, Goldgar D, Devilee P, Bishop DT, Weber B, Lenoir G, Chang-Claude J, et al.: Genetic heterogeneity and penetrance analysis of the BRCA1 and BRCA2 genes in breast cancer families. The Breast Cancer Linkage Consortium. Am J Hum Genet 1998, 62:676-689.

2. Sidransky D, Tokino T, Helzlsouer K, Zehnbauer B, Rausch G, Shelton B, Prestigiacomo L, Vogelstein B, Davidson N: Inherited p53 gene mutations in breast cancer. Cancer Res 1992, 52:2984-2986.

3. Lynch ED, Ostermeyer EA, Lee MK, Arena JF, Ji H, Dann J, Swisshelm K, Suchard D, MacLeod PM, Kvinnsland S, et al.: Inherited mutations in PTEN that are associated with breast cancer, cowden disease, and juvenile polyposis. Am J Hum Genet 1997, 61:1254-1260.

4. Chenevix-Trench G, Spurdle AB, Gatei M, Kelly H, Marsh A, Chen X, Donn K, Cummings M, Nyholt D, Jenkins MA, et al.: Dominant negative ATM mutations in breast cancer families. J Natl Cancer Inst 2002, 94:205-215.

5. Bernstein JL, Teraoka SN, John EM, Andrulis IL, Knight JA, Lapinski $\mathrm{R}$, Olson ER, Wolitzer AL, Seminara D, Whittemore AS, Concannon $\mathrm{P}$ : The $\mathrm{CHEK2}{ }^{*} 1100 \mathrm{delC}$ allelic variant and risk of breast cancer: screening results from the Breast Cancer Family Registry. Cancer Epidemiol Biomarkers Prev 2006, 15:348-352.

6. Khanna KK, Jackson SP: DNA double-strand breaks: signaling, repair and the cancer connection. Nat Genet 2001, 27:247-254.

7. Benson FE, Stasiak A, West SC: Purification and characterization of the human Rad51 protein, an analogue of E. coli RecA. Embo J 1994, 13:5764-5771.

8. Shinohara A, Ogawa H, Matsuda Y, Ushio N, Ikeo K, Ogawa T: Cloning of human, mouse and fission yeast recombination genes homologous to RAD51 and recA. Nat Genet 1993, 4:239-243.

9. Richardson C: RAD51, genomic stability, and tumorigenesis. Cancer Lett 2005, 218:127-139.

10. Tsuzuki T, Fujii Y, Sakumi K, Tominaga Y, Nakao K, Sekiguchi M, Matsushiro A, Yoshimura Y, Morita T: Targeted disruption of the Rad51 gene leads to lethality in embryonic mice. Proc Nat Acad Sci USA 1996, 93:6236-6240.

11. Takahashi E, Matsuda Y, Hori T, Yasuda N, Tsuji S, Mori M, Yoshimura Y, Yamamoto A, Morita T, Matsushiro A: Chromosome mapping of the human (RECA) and mouse (Reca) homologs of the yeast RAD51 and Escherichia coli recA genes to human (15q15.1) and mouse (2F1) chromosomes by direct R-banding fluorescence in situ hybridization. Genomics 1994, 19:376-378.

12. Wick W, Petersen I, Schmutzler RK, Wolfarth B, Lenartz D, Bierhoff E, Hummerich J, Muller DJ, Stangl AP, Schramm J, et al.: Evidence for a novel tumor suppressor gene on chromosome 15 associated with progression to a metastatic stage in breast cancer. Oncogene 1996, 12:973-978.

13. Gonzalez R, Silva JM, Dominguez G, Garcia JM, Martinez G, Vargas J, Provencio M, Espana P, Bonilla F: Detection of loss of heterozygosity at RAD51, RAD52, RAD54 and BRCA1 and BRCA2 loci in breast cancer: pathological correlations. $\mathrm{Br} J$ Cancer 1999, 81:503-509.

14. Hedenfalk I, Ringner M, Ben-Dor A, Yakhini Z, Chen Y, Chebil G, Ach R, Loman N, Olsson H, Meltzer P, et al.: Molecular classification of familial non-BRCA1/BRCA2 breast cancer. Proc Nat/ Acad Sci USA 2003, 100:2532-2537.

15. Yoshikawa K, Ogawa T, Baer R, Hemmi H, Honda K, Yamauchi A, Inamoto T, Ko K, Yazumi S, Motoda H, et al:: Abnormal expression of BRCA1 and BRCA1-interactive DNA-repair proteins in breast carcinomas. Int J Cancer 2000, 88:28-36.

16. Ma XJ, Salunga R, Tuggle JT, Gaudet J, Enright E, McQuary P, Payette T, Pistone M, Stecker K, Zhang BM, et al.: Gene expression profiles of human breast cancer progression. Proc Natl Acad Sci USA 2003, 100:5974-5979.

17. Maacke H, Opitz S, Jost K, Hamdorf W, Henning W, Kruger S, Feller AC, Lopens A, Diedrich K, Schwinger E, Strurzbecher HW: Over-expression of wild-type Rad51 correlates with histological grading of invasive ductal breast cancer. Int J Cancer 2000, 88:907-913. 
18. Raderschall E, Stout K, Freier S, Suckow V, Schweiger S, Haaf T: Elevated levels of Rad51 recombination protein in tumor cells. Cancer Res 2002, 62:219-225.

19. Baumann $P$, West SC: The human Rad51 protein: polarity of strand transfer and stimulation by hRP-A. EMBO J 1997, 16:5198-5206.

20. Thacker J: The RAD51 gene family, genetic instability and cancer. Cancer Lett 2005, 219:125-135.

21. Bell DW, Wahrer DC, Kang DH, MacMahon MS, FitzGerald MG, Ishioka C, Isselbacher KJ, Krainer M, Haber DA: Common nonsense mutations in RAD52. Cancer Res 1999, 59:3883-3888.

22. Kato $M$, Yano $K$, Matsuo $F$, Saito $H$, Katagiri $T$, Kurumizaka $H$, Yoshimoto M, Kasumi F, Akiyama F, Sakamoto G, et al.: Identification of Rad51 alteration in patients with bilateral breast cancer. J Hum Genet 2000, 45:133-137.

23. Rapakko K, Heikkinen K, Karppinen SM, Winqvist R: Screening for RAD51 and BRCA2 BRC repeat mutations in breast and ovarian cancer families. Cancer Lett 2005, 236:142-147.

24. Eng C, Brody LC, Wagner TM, Devilee P, Vijg J, Szabo C, Tavtigian SV, Nathanson KL, Ostrander E, Frank TS: Interpreting epidemiological research: blinded comparison of methods used to estimate the prevalence of inherited mutations in BRCA1. J Med Genet 2001, 38:824-833.

25. Jones AC, Austin J, Hansen N, Hoogendoorn B, Oefner PJ, Cheadle JP, O'Donovan MC: Optimal temperature selection for mutation detection by denaturing HPLC and comparison to single-stranded conformation polymorphism and heteroduplex analysis. Clin Chem 1999, 45:1133-1140.

26. Mann GJ, Thorne H, Balleine RL, Butow PN, Clarke CL, Edkins E, Evans GM, Fereday S, Haan E, Gattas M, et al.: Analysis of cancer risk and BRCA1 and BRCA2 mutation prevalence in the kConFab familial breast cancer resource. Breast Cancer Res 2006, 8:R12.

27. Heath AC, Bucholz KK, Madden PA, Dinwiddie SH, Slutske WS, Bierut LJ, Statham DJ, Dunne MP, Whitfield JB, Martin NG: Genetic and environmental contributions to alcohol dependence risk in a national twin sample: consistency of findings in women and men. Psychol Med 1997, 27:1381-1396.

28. Primer3 [http://cbr-rbc.nrc-cnrc.gc.ca/cgi-bin/ primer3 www.cgi]

29. DHPLC Melt program [http://insertion.stanford.edu/melt.html]

30. Singer-Sam J, LeBon JM, Dai A, Riggs AD: A sensitive, quantitative assay for measurement of allele-specific transcripts differing by a single nucleotide. PCR Methods Appl 1992, 1:160-163.

31. Schwartz S, Zhang Z, Frazer KA, Smit A, Riemer C, Bouck J, Gibbs R, Hardison R, Miller W: PipMaker - a web server for aligning two genomic DNA sequences. Genome Res 2000, 10:577-586.

32. Alex Dong Li's SpliceSiteFinder [http://www.genet.sick kids.on.ca/ ali/splicesitefinder.html]

33. Schmutte C, Tombline G, Rhiem K, Sadoff MM, Schmutzler R, von Deimling A, Fishel R: Characterization of the human Rad51 genomic locus and examination of tumors with 15q14-15 loss of heterozygosity (LOH). Cancer Res 1999, 59:4564-4569.

34. NCBI Entrez SNP database [http://www.ncbi.nlm.nih.gov/ projects/SNP/] 